\title{
Slowing of central conduction in X-linked Charcot-Marie-Tooth neuropathy shown by brain stem auditory evoked responses
}

\author{
Garth Nicholson, Alastair Corbett
}

\begin{abstract}
Background-The most common form of CMT with slow nerve conduction velocities (CMT type I) is CMT1A, caused by a submicroscopic duplication of a region of DNA on chromosome 17 including the PMP22 gene. This gene is expressed in peripheral nerve but not in the CNS. The second most common form is CMTX, caused by mutations in the connexin 32 gene in the $\mathrm{X}$ chromosome. Connexin 32 is expressed both in brain and in peripheral nerve. These molecular variants are difficult to distinguish clinically.

Methods-Brain stem auditory evoked responses (BAERs) were measured in patients with CTMX and CMT1A.

Results-BAERs showed central conduction slowing in male patients with CMTX which did not overlap the normal range. Patients with CMT1A had a delay in wave I latency but otherwise normal responses. These results are consistent with the pattern of expression of PMP22 in the peripheral portion of the eighth nerve (myelinated by Schwann cells) and of connexin 32 in the central portion in the brainstem auditory pathways (myelinated by oligodendrocytes). This is the first evidence for central involvement in CMTX. Conclusion-BAERs are useful to distinguish CMTX from CMT1A and may assist selection of appropriate patients for connexin 32 mutation analysis.
\end{abstract}

(F Neurol Neurosurg Psychiatry 1996;61:43-46)

Keywords: X-linked Charcot-Marie-Tooth neuropathy; brainstem auditory evoked responses

Charcot-Marie-Tooth (CMT) neuropathy is the commonest group of genetic disorders of peripheral nerve with prevalence estimates ranging from one in 3500 to 8000 population. ${ }^{1-3}$ There are two subgroups of CMT according to nerve conduction velocity. That with slow motor nerve conduction velocities (hereditary motor and sensory neuropathies type I, HMSN I) is more common than CMT type II (HMSN II), an axonal disorder with relatively normal conduction velocities. ${ }^{4}$ Molecular genetic techniques have recently shown that CMT type I is heterogenous and includes disorders caused by abnormalities in Schwann cell myelin proteins. ${ }^{45}$ The most common variety of CMT type I is CMT1A.
Some lines of evidence suggest that CMT1A is due to an overdose of the peripheral myelin protein, PMP22, resulting from a duplication of the region of DNA including the PMP22 gene. ${ }^{67} \mathrm{CMT} 1 \mathrm{~B}$ is rare and is caused by mutations in myelin protein zero (Po) ${ }^{8}$ Both the PMP22 and Po proteins are expressed in compact myelin.

The next most common form of CMT type I after CMT1A, has a locus on the X chromosome (X-linked CMT, CMTX) and has recently been shown to be caused by mutations in the gap junction gene connexin $32 .{ }^{9}$ This may account for $10 \%$ to $20 \%$ of the total number of type I families. ${ }^{4}$ No single test can distinguish CMTX from other varieties of CMT type I. Possible CMTX families can be recognised if there is no male to male inheritance of the disease and when affected patients have no chromosome 17 DNA duplication. Additional evidence towards a diagnosis of CMTX is provided if intermediate range motor nerve conduction velocities are found in female CMT carriers. ${ }^{10}$ This is not always possible as males with CMTX may present as isolated or sporadic cases of CMT when the female carrier mother is asymptomatic. As it is difficult and expensive to confirm the presence of CMTX connexin32 mutations by DNA sequencing, there is a need for further clinical tests to accurately define those with CMTX.

A total of 33 different mutations have now been described in the gap junction protein connexin32 in 39 unrelated families with CMTX. ${ }^{11}$ The protein is expressed in several tissues $^{12}$ including glia and neurons in the CNS. Connexin 32 is part of a family of gap junction proteins and may have structural and pore properties. ${ }^{13}$ In peripheral nerve connexin32 is found in Schwann cell membranes in the nodes of Ranvier and in the SchmidtLantermann incisures but not in compact myelin. ${ }^{9}$

Connexin 32 transports small molecules up to $1000 \mathrm{Da}$. Such small molecules may have a nutritional or messenger function. When three CMTX mutations were expressed in a paired oocyte expression system, loss of junctional conductance occurred showing that connexin32 mutations may destroy pore function. ${ }^{14}$

As connexin 32 is expressed in the CNS in both glia and neurons and as some of our patients had mild deafness, we tested hearing and brain stem auditory evoked responses (BAERs) in 10 male patients with CMTX, to determine if auditory pathways are affected in CMTX. Female patients with CMTX were 


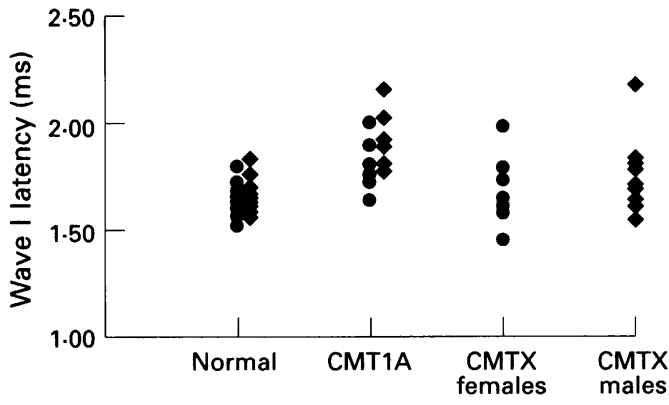

Figure 1 Wave I brain stem auditory evoked response latencies. Latency (ms) of wave peak 1 in normal male patients (10) and female patients (9), CMT1A male patients $(n=10)$ and female patients $(n=7)$, and CMTX male (10) and female $(n=8)$ groups; see table for statistics.

included as a separate group in this study as the disease is variably expressed in females and they are often only mildly affected. This is due to the effects of lyonisation (variable $\mathrm{X}$ chromosome inactivation). ${ }^{10}$ The BAERs in patients with CMTX were compared with those in patients with CMT1A and those in normal, unaffected people.

\section{Methods}

PATIENT SELECTION

Consecutive patients with CMTX and CMT1A presenting to the Concord Hospital CMT clinic for review were invited to participate in this study. Each was questioned about the presence of deafness. Patients with CMTX or CMT1A were defined by the presence of connexin 32 mutations or chromosome 17 duplications respectively.

CMT MUTATIONS

Connexin 32 mutations were detected by DNA sequencing of double stranded polymerase chain reaction products as described by Bergoffen et al. ${ }^{9}$ The following CMTX mutations were detected: Pro $158 \mathrm{Ala}$, Val $35 \mathrm{Met}$, Ser $182 \mathrm{Thr}$, deletion $110-116,{ }^{15}$ Arg 220 to stop, 1 base pair deletion base 158 giving stop at 195. The CMT1A duplication was determined with probe VAW409R3 (D17S122) and densitometry of autoradiographs ${ }^{6}$ and pulse field gel analysis. ${ }^{16}$

\section{BRAIN STEM AUDITORY EVOKED RESPONSE STUDIES}

The BAERs were elicited with monaural click stimuli of $0.1 \mathrm{~ms}$ duration with both rarefaction and condensation polarity and were recorded on a Medlec Sensor. Click hearing threshold was determined and a stimulus intensity of $70 \mathrm{~dB}$ above threshold was used. The right and left ears were stimulated independently with the unstimulated ear masked with white noise at an intensity of $30 \mathrm{~dB}$. Surface electrodes were used with the reference electrode placed at $\mathrm{Cz}$ and the active electrodes placed on the ear lobes at $\mathrm{Al}$ and A2. Click stimuli were delivered at a rate of 10 $\mathrm{Hz}$. The BAERs were recorded with a low frequency filter of $3 \mathrm{~Hz}$ and a high frequency filter of $3 \mathrm{kHz}$. Analysis time of $10 \mathrm{~ms}$ after the

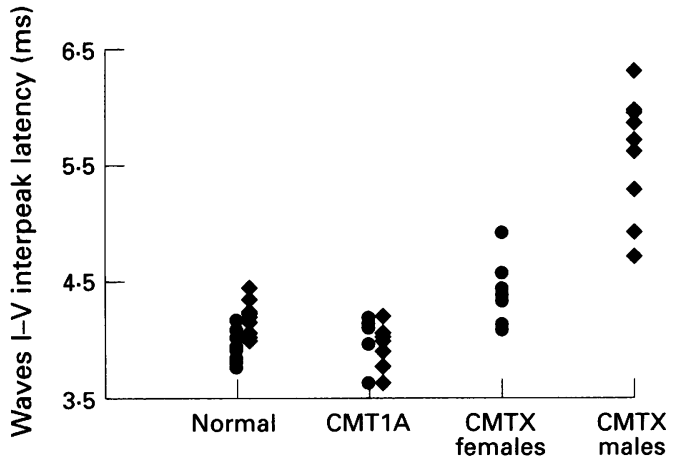

Figure 2 Wave I-V interpeak brain stem auditory evoked response latencies. Interwave latency (ms) between wave peaks 1 and 5 in the groups shown in fig 1 (normal patients, CMT1A, and CMTX male and female groups); see table for statistics.

stimulus was used and 1024 responses averaged with two runs of both polarities recorded for each ear. The latencies for peaks of waves 1 to 5 were measured for further analysis.

\section{Results}

SYMPTOMATIC DEAFNESS

One woman with CMT1 (aged 77) and two men with CMTX (aged 70 and 35) had hearing loss on questioning. The 35 year old was slightly deaf in one ear $(-25 \mathrm{~dB}$ at $6 \mathrm{kHz})$ and had difficulty hearing in a crowd of people. Audiograms detected mild high frequency sensorineural deafness in these three patients, which was insufficient to prevent BAERs.

\section{BRAIN STEM AUDITORY EVOKED RESPONSE} STUDIES

Control values for BAERs were obtained from 19 normal subjects ranging in age from 22 to 51 (mean 34.6) years. The 17 patients with CMT1A ranged in age from 17 to 77 (mean 42.9) years and the 10 male patients with CMTX were aged 12 to 70 (mean 34.3 ) years. Eight female patients with CMTX were aged 11 to 78 (mean 37.4) years. Satisfactory BAER waveforms were obtained for all subjects. Waveforms were not attenuated in either patients with CMT1A or those with CMTX.

The mean click threshold for the 19 control subjects was 11.97 (SD 3.95) $\mathrm{dB}$, the 17 patients with CMT1A 15.88 (SD 15.49) dB, the male patients with CMTX $9 \cdot 25$ (SD 7.99) $\mathrm{dB}$, and the female patients with CMTX 14.38 (SD 7.99) dB. The click thresholds for male and female patients with CMTX were not significantly different from controls.

Wave I latencies were significantly longer in patients with CMT1A compared with controls (table) suggesting delayed conduction in the distal eighth nerve. Later BAER wave latencies and interwave latencies beyond wave I for CMT1A were not significantly different from controls (table).

Wave I latencies for patients with CMTX were not significantly different from controls, unlike the patients with CMT1A (table). Later waveforms beyond wave $I$ and $I-V$ interwave latencies were all significantly delayed in the 
Mean (SD) BAER wave peak latencies (ms)

\begin{tabular}{|c|c|c|c|c|}
\hline Latency & $\begin{array}{l}\text { Normal } \\
\text { subjects }\end{array}$ & $C M T 1 A$ & $\begin{array}{l}\text { CMTX } \\
\text { males }\end{array}$ & $\begin{array}{l}\text { CMTX } \\
\text { females }\end{array}$ \\
\hline Wave I & $1.65(0.08)$ & $\begin{array}{l}1.85(0.13) \\
P<0.001\end{array}$ & $1 \cdot 74(0 \cdot 18)$ & $1 \cdot 67(0 \cdot 16)$ \\
\hline Wave II & $2 \cdot 78(0 \cdot 11)$ & $2.90(0 \cdot 16)$ & \multirow{7}{*}{$\begin{array}{l}3.16(0.21) \\
P<0.000 \\
4.37(0.22) \\
P<0.000 \\
5.99(0.45) \\
P<0.001 \\
7.25(0.51) \\
P<0.001 \\
2.64(0.14) \\
P<0.001 \\
2.88(0.45) \\
P<0.001 \\
5.51(0.53) \\
P<0.001\end{array}$} & $2 \cdot 28(0 \cdot 22)$ \\
\hline Wave III & $3.82(0 \cdot 14)$ & $3.98(0.19)$ & & $3.89(2 \cdot 13)$ \\
\hline Wave IV & $4 \cdot 96(0 \cdot 15)$ & $5 \cdot 13(0 \cdot 20)$ & & \multirow{3}{*}{$\begin{array}{l}5 \cdot 13(0.17) \\
\mathrm{P}<0.05 \\
6.03(0 \cdot 29) \\
\mathrm{P}<0.01 \\
2 \cdot 22(0 \cdot 12)\end{array}$} \\
\hline Wave V & $5 \cdot 17(0 \cdot 18)$ & $5.85(0 \cdot 25)$ & & \\
\hline Interwave I-III & $2 \cdot 17(0 \cdot 13)$ & $2 \cdot 13(0 \cdot 13)$ & & \\
\hline Interwave III-V & $1.89(0.13)$ & $1 \cdot 87(0 \cdot 16)$ & & \multirow{2}{*}{$\begin{array}{l}2 \cdot 14(0 \cdot 19) \\
P<0 \cdot 001 \\
4 \cdot 36(0 \cdot 28) \\
P<0.01\end{array}$} \\
\hline Interwave I-V & $4 \cdot 06(0 \cdot 17)$ & $4 \cdot 00(0 \cdot 18)$ & & \\
\hline
\end{tabular}

Mean latencies for right and left ears using rarefaction and condensation click stimuli in norma subjects (10 male and nine female patients), patients with CMT1A (10 males and seven females) and patients with CMTX (10 males and eight females). P values are for two tailed independent sample $t$ tests comparing the CMT groups with the control group of the appropriate sex. interpeak delays. ${ }^{23}$ Patients with both wave I delay and interpeak delay were reported by Garg et al. ${ }^{24}$ All these studies were performed before it was possible to separate the two common forms of HMSN I-CMT1A and CMTX.

In these earlier studies dominant inheritance was not strictly defined by the presence of male to male inheritance and some multigeneration families without male to male inheritance which could be X-linked families were included. Interpeak BAER delays were probably due to unrecognised cases of CMTX

We had two patients with both wave I delay and increased interpeak latency indicating that both central and peripheral slowing may occur in CMTX. This is to be expected as considerable slowing of nerve conduction occurs in CMTX but on average is $10 \mathrm{~m} / \mathrm{s}$ faster than in CMT1A.

Our results for CMT1A are similar to those reported in CMT type I by Scaioli et al, ${ }^{19}$ who found delay in wave peak I consistent with slowing of conduction in the peripheral acoustic nerve. Delay in wave $I$ has also been reported in demyelination in the GuillainBarré syndrome. ${ }^{25}$

Raglan et $a l^{22}$ thought that BAER abnormalities explain hearing loss in HMSN I but our results showed that all our male patients with CMTX had interpeak delays but only two had symptomatic hearing loss and mild high frequency loss on audiograms. One had mild unilateral high frequency loss and the other, like the severely affected patients of Raglan et al, ${ }^{22}$ was an older patient. This patient and the patient with CMT1A with hearing loss were the two oldest members of the study.

Interpeak delay may be present from birth as even patients as young as 8 years have delays as prominent as older subjects. Therefore, slowing of central conduction may be analagous to the lifelong slowing of nerve conduction in CMT1 $\mathrm{A}^{2627}$ and deafness is an age dependent central phenomenon equivalent to the age dependent decrease in motor action potential amplitude in CMT1A. ${ }^{26}$

This study is the first evidence of central conduction delay and auditory pathway abnormalities in CMTX and further detailed studies of other central functions are warranted. The delay was unrelated to hearing loss. No central involvement has yet been found in CMT1A. The pathophysiological basis of these findings requires further investigation and suggests a central myelination defect and possible axonal effects in CMTX.

The expert technical assistance of Michele Ingleton and Catherine McKay in carrying out BAER testing and Leonie Yeung and Melissa Gordon for the CMTX and CMT1A mutation analysis is gratefully acknowledged. This work was assisted by grants from the Muscular Dystrophy Association of the USA, the National Health and Medical Research Council of Australia, the Australian Brain Foundation (Northwest Golden Bowl Committee), and the Charcot-Marie-Tooth Association of Australia.

1 Skre $\mathbf{H}$. Genetic and clinical aspects of Charcot-MarieTooth disease. Clin Genet 1974;6:98-118.

2 MacMillan JC, Harper PS. The Charcot-Marie-Tooth syndrome: clinical aspects from a population study in south Wales, UK. Clin Genet 1994;45:128-34. 
3 Emery AEH. Population frequencies of inherited neuromuscular diseases-a world survey. Neuromuscul Disord 1991;1:19-29.

4 Ionasescu V. Charcot-Marie-Tooth neuropathies: from clinical description to molecular genetics. Muscle Nerve 1995; 18:267-75

5 Nicholson GA. Myelin gene dosage and mutation in the hereditary motor and sensory neuropathies: a review. $\mathcal{F}$ Neurol Neurosurg Psychiatry 1995;58:523-5.

6 Raeymaekers P, Timmerman V, Nelis E, et al. Duplication in chromosome $17 \mathrm{p} 11.2$ in Charcot-Marie-Tooth neuropathy type 1a (CMT 1A). Neuromuscul Disord 1991; ropathy

7 Lupski JR, Montes de Oca-Luna R, Slaugenhaupt S, et al. DNA duplication associated with Charcot-Marie-Tooth disease type 1A. Cell 1991;66:219-32.

8 Hayasaka K, Himoro M, Sato W, et al. Charcot-MarieTooth type $1 \mathrm{~B}$ is associated with mutations of the myelin Po gene. Nature Genetics 1993;5:31-4

9 Bergoffen J, Scherer SS, Wang S, et al. Connexin mutations in X-Linked Charcot-Marie-Tooth disease. Science 1993; 262:2039-42

10 Nicholson G, Nash J. Intermediate nerve conduction velocities define X-linked Charcot-Marie-Tooth neuropathy families. Neurology 1993;43:2558-64.

11 Bone LJ, Dahl BA, Lensch BS, et al. New connexin 32 mutations associated with X-linked Charcot-Mariemutations associated with $\mathrm{X}$-linked $\mathrm{Ch}$

12 Dermietzel R, Spray DC. Gap-junctions in the brain: where, what type, how many and why? TINS 1993;16: $186-92$

13 Unwin PNT, Zampighi G. Structure of the junction between communicating cells. Nature 1980;283:545-9.

14 Bruzzone R, White TW, Scherer SS, Fischbeck KH, Paul
DL. Null mutations of connexin32 in patients with XDL. Null mutations of connexin32 in patients with X1253-60

15 Cherryson AK, Yeung L, Kennerson ML, Nicholson GA. Mutational studies in X-linked Charcot-Marie-Tooth disease (CMTX). Am f Hum Genet 1994;55(suppl): 1261 .
16 Lupski JR. An inherited DNA rearrangement and gene dosage effect are responsible for the most common autosomal dominant peripheral neuropathy: Charcot-MarieTooth disease type1A. Clin Res 1992;40:645-52.

17 Chiappa KP. Evoked potentials in clinical medicine; Raven Press: New York, 1990

18 Gadoth N, Gordon CR, Bleich N, Pratt H. Three modality evoked potentials in Charcot-Marie-Tooth disease (HMSN-1). Brain Dev 1991;13:91-4

19 Scaioli V, Pareyson D, Avanzini G, Sghirlanzoni AF. Response and somatosensory and brainstem auditory evoked potential studies in HMSN type-I and type-II. evoked potential studies in HMSN type-1 and

20 Kowalski JW, Rasheva M, Zakrzewska B. Visual and brainstem auditory evoked potentials in hereditary motor-senstem auditory evoked potentials in hereditary motor-sen-
sory neuropathy. Electromyogr Clin Neurophysiol 1991;31: sory neurop

21 Satya-Murti S, Cacace AT. Abnormal auditory evoked potentials in hereditary motor-sensory neuropathy. $A n n$ Neurology 1979;5:445-8.

22 Raglan E, Prasher D, Trinter E, Rudge P. Auditory function in hereditary motor sensory neuropathy. Acta Otolaryngol 1987;103:50-5.

23 Triantafyllou N, Rombos A, Athanasopoulou H, Siafakas A, Malliara Loulakaki S. Electrophysiological study (EEG, VEPs, BAEPs) in patients with Charcot-MarieTooth (type HMSN I) disease. Electromyogr Clin Neurophysiol 1989;29:259-63.

24 Garg BP, Markand ON, Bustion F Brainstem auditory evoked responses in hereditary motor-sensory neuropaevoked responses in hereditary motor-sensory

25 Nelson KR, Gilmore RL, Massey A. Acoustic nerve conduction abnormalities in Guillain-Barré syndrome.
duction duction abnormalities

26 Nicholson GA. Penetrance of the hereditary motor and sensory neuropathy ia-mutation; assessment by nerve conduction studies. Neurology 1991;41:547-52.

27 Berciano J, Combaros O, Calleja J, Polo JM, Leno C. The application of nerve conduction and clinical studies to genetic counselling in hereditary motor and sensory neuropathy type I. Muscle Nerve 1989;12:302-6. 